\title{
Un Arqueólogo en la ciudad: en los inicios de un ensayo
}

\author{
A Manolo BENDALA, zoon politikon \\ LaURO OLMO ENCISO \\ (lauro.olmo@uah.es)
}

\section{Resumen}

La arqueología como ciencia histórica y social debe incrementar su participación en el debate sobre la caracterización de la ciudad actual, que es también el debate sobre la sociedad actual. Este artículo defiende la oferta de lo que nuestra ciencia genera para el conocimiento de la realidad urbana a partir de una praxis que, partiendo de la Memoria, se construye en la contemporaneidad.

Palabras clave: Arqueología y Paisaje urbano, arqueología social, urbanismo y arqueología, ciudad histórica, arqueología como investigación.

\section{Summary}

Archaeology as historical and social science should increase their participation in the debate on the characterization of the present city, which is also the debate about our social model. This paper defends the offer of what generates our science for understanding urban reality from a praxis that, based on the Memory, is constructed in the contemporaneity.

Keywords: Archaeology and Urban Landscape, Social Archaeology, Urban planning and Archaeology, Historical City, Archaeology as Research.

\section{Tiempo y EsPaCiO}

"La ciudad esta hecha de relaciones entre las dimensiones de su espacio y los acontecimientos de su pasado"

(Italo Calvino, Las ciudades invisibles)

La asunción para el tratamiento del paisaje urbano, de estas dimensiones de espacio y tiempo, permite también presentar la Memoria urbana desde la perspectiva de la arqueología, argumentada, por tanto, desde la propia praxis actual de esta ciencia histórica. Se trata de defender y reflexionar sobre el concepto de ciudad histórica, como ese espacio que supera los límites reduccionistas impuestos sobre la consideración de lo "histórico" en la ciudad actual, a través de los cuales se sacralizan espacios convencionalmente definidos así -cascos o centros históricos- o lugares aislados de su contexto -monumentos-. Es decir, de como se ha ido construyendo una imagen histórica del pasado a través de las preguntas generadas desde el presente, desde los diferentes presentes. Todo ello se inscribe en el proceso de desarrollo y transformación de nuestra concepción del Patrimonio Histórico asociada al paso del Tiempo en un determinado Espacio. Desde el origen de esta concepción, a partir de la formulación de estos dos grandes principios del conocimiento kantiano -espacio y tiempo-, esta se ha ido abriendo a nuevas dimensiones espaciales y temporales. Y es así como a partir de estos presupuestos se construyó una idea de ciudad que fue cambiando y transformándose. Se desarrolló dia- 
crónicamente reinterpretando sucesivamente un espacio histórico, un pasado a partir de resignificaciones de las diferentes formas de abordar la Memoria construidas desde las sucesivas contemporaneidades. Concepto éste de contemporaneidad que encuentra su primera formulación con Alois Riegl quien indicó, cómo el cambio de perspectiva patrimonial en el culto a los monumentos está fuertemente condicionado por la mirada subjetiva de una época y de su historia en relación con el pasado. Algo en lo que, unas décadas más tarde, incidió Maurice Halbwachs, al señalar como la Memoria es una reconstrucción parcial y selectiva del pasado, cuyos puntos de referencia están definidos por los intereses y por la conformación de la sociedad presente y, por tanto, como hay que recordar estamos ante una acción que se produce en el presente y que del presente depende (Halbwachs, 1987: 23 y 28, citado en Ricci, 2006: 73-74). Es esencial entender que la propia concepción sobre el origen de la ciudad europea, convencionalmente construida a partir de una reinterpretación de los espacios urbanos de Grecia y Roma, y, posteriormente, de la ciudad medieval, transmite algo también de extrema importancia, y siempre a ser tenido en cuenta: nuestro concepto actual de ciudad es un concepto europeo que nace de la Ilustración, y que representa nuestra forma de interpretar, de aproximarnos, al paisaje urbano. Y todo ello a partir de la fecunda reflexión de la ciudad producida a lo largo de la modernidad, desde los utopistas de principios del XIX (Owen, Fourier....) hasta lo implícito en el pensamiento del movimiento moderno. De hecho cuando, en la actualidad, proclamamos la crisis de la ciudad, estamos determinando la crisis de la ciudad europea, de la ciudad de la Razón, de la construcción espacial a partir de la cual se define una ciudad en la que es imprescindible enunciar y precisar ésta, en tanto que Historia y Memoria (Anny Vrychea, en Tsiomis, 1998:76).

Una de las consecuencias de la industrialización y la determinante aparición de nuevos espacios urbanos, produjo a mediados del siglo XIX una sensibilización por una parte del mundo intelectual sobre la protección de los conjuntos urbanos preindustriales. Esto supuso que la naciente noción de patrimonio histórico urbano se construyera a contracorriente del proceso de urbanización dominante, por tanto, que la percepción de la ciudad como objeto de valor histórico se desarrollara a partir de la transformación del espacio urbano que provocó la industrialización (Choay,
2007:164). Construcción histórica que se inscribió y formó parte del debate y reflexión sobre el futuro de la ciudad industrial, constituyendo un aspecto interesante de este debate la relación conflictiva entre la sacralización de espacios históricos urbanos y la naciente teoría del urbanismo, desarrollada a partir de la obra de Ildefonso Cerdá. Y todo dentro de un contexto, no exento de polémica, sobre la consideración y estrategias de actuación en los espacios históricos de las ciudades que se fue desarrollando a lo largo de todo un siglo. A partir de la idealización de una nostalgia por el pasado, esta se abordará desde diferentes ópticas que reflejan tomas de posición ante las transformaciones sociales que se estaban produciendo y como éstas afectaban y se expresaban en los nuevos paisajes urbanos de la ciudad industrial. Así las primeras controversias surgirán entre John Ruskin y Eugéne Viollet-le-Duc, defensor el primero de la conservación integral de la estructura de la ciudad antigua, poseedora de un valor identitario, mientras que el segundo abogaba por el mantenimiento de espacios del pasado en la nueva realidad urbana industrial a través de la revisión de esa herencia urbana. Esta atención al valor histórico, generó un impulso para una reflexión más operativa sobre el futuro de las ciudades industriales que iba adquiriendo forma concienzuda en los estudios de los urbanistas. Así, Ildefonso Cerdá planificó un desarrollo urbano de nueva planta preservando el espacio histórico más característico del total que había constituido, en su caso, la ciudad antigua de Barcelona; Camillo Sitte, que no militó a favor de la conservación de los centros históricos (Choay, 2007: 163-168), defendió la necesidad de un estudio morfológico de las ciudades antiguas a la búsqueda de principios y configuraciones espaciales que mantenidos a través del tiempo constituyeran herramientas heurísticas imprescindibles para el urbanista; Gustavo Giovannoni (ibidem: 175-180), otorgó a los conjuntos urbanos antiguos un valor de uso y un valor museal, considerando a los centros históricos como un tejido viviente, que debía ser integrado en los planes de ordenación. Junto a estos habría que incluir la obra de Arturo Soria y Mata, Josef Stübben, Otto Wagner, Tony Garnier (Tsiomis, 1998: 137-138). Ejemplos todos estos que responden a diferentes perspectivas sobre cómo la sociedad de la modernidad se fue abriendo a nuevas dimensiones espaciales y cómo se las conceptualizó. Sin embargo, hay que notar como todas partían de un mismo supuesto, la considera- 
ción de un espacio urbano con límites espaciales y cronológicos precisos, el centro histórico, al que se le otorgaba el valor de histórico, de monumento, habrá que esperar a bien entrado el siglo XX en que se desarrolla la crítica del espacio entendido con un sentido estrictamente geométrico, entendiendo éste como una construcción social (Lefebvre, 1991).

Nuestra preocupación por fijar un origen, un punto de partida, ha llevado a establecer el, ya citado, nacimiento de la ciudad europea a partir de la interpretación de la Polis griega y la Civitas romana. La investigación arqueológica ha sido fundamental para investigar y explicar la organización y estructuración de estos espacios así como para establecer el marco evolutivo de su urbanismo - en el que la construcción taxonómica ha tenido un papel primordial - y su relación con la sociedad que lo generó. Pero también es cierto, que se podría haber profundizado más en la diferencia y caracterización de cada una de ellas. Porque lo que es evidente es que si queremos buscar un origen, entonces habría que concluir que la noción europea de ciudad se construye a partir de la interpretación de la idea romana. De esa idea de ciudad, argumentada por Cacciari, como lugar en el que personas de diversos orígenes convergen y convienen en aceptar una Ley, de una idea de ciudadanía romana que no tiene ninguna raíz étnicoreligiosa "es grandiosa la idea de que aquello que nos une, que nos junta, no se basa en un origen, sino más bien en un fin" (Cacciari, 2009: 10 y 21). Pero también, como argumenta este autor, portamos la nostalgia de la Polis, de la ciudad con origen que entra en conflicto con la tensión hacia la universalidad. De la Polis como la morada, el lugar donde una gente determinada tiene su sede, su propio éthos (ibidem: 8-10). Cual es la idea de ciudad por la que optamos ¿ésta? O la gran idea romana de gente diversa de diferentes procedencias, con diferentes lenguas y religiones, pero todos bajo la misma ley ¿Qué referencia escogemos? ¿El origen o el fin? ¿Los lazos de estirpe o la Ley? Este es el debate actual, la ciudadanía frente a la etnia, la ciudadanía frente a la particularidad, la inclusión frente a la exclusión, el universalismo de la modernidad frente a la deconstrucción de la postmodernidad. Debate de ya larga tradición en nuestro modelo social, pero que como en otros periodos, se proyecta en el paisaje urbano y como consecuencia, sobre la consideración del espacio patrimonial. Y claro, todo ello obliga a escoger opción, ya que asistimos en la actualidad a un cambio radical de perspectiva

La ciudad, el tratamiento del paisaje, como lo entendemos en Occidente, en Europa, en la tradición del "Buon Governo" de Ambrogio Lorenzetti, estaba siendo destruida por el ímpetu conjunto de la industria y del mercado, dando origen a la Metrópoli (Cacciari, 2009:27). Bien es verdad que ahora, cuando prácticamente ya no queda ni la industria, nos encontramos ante la hegemonía del mercado. De un mercado que, desde su acepción más conservadora, parece haber encontrado solución a una ciudad que le era incómoda desde hace ya varias décadas. De hecho, ya Henri Ford había marcado una dirección hace casi un siglo cuando dictaminó "Solucionaremos el problema de las ciudades abandonándolas". La revitalización actual de esta concepción, la crítica al modelo de ciudad convivencial, se inscribía, por tanto, dentro de una línea interpretativa defensora de otro paisaje urbano, en definitiva, de otro paisaje social. Dentro de ella, quizás una de la expresiones más significativas sobre este proceso es la manifestada por el ideólogo conservador George Gilder, "nos encaminamos hacia la muerte de las ciudades, el equipaje sobrante de la era industrial" (1995: 56).

En la actualidad en nuestro ámbito social, en nuestro modelo social occidental, el mundo es la ciudad. Todo el territorio se encuentra urbanizado, desde las megalópolis, a las áreas periurbanas que se extienden a través de los sistemas veloces de transporte y de comunicación por unas zonas rurales que cada vez lo son menos. El nuevo tejido urbano configura un escenario territorial metropolitano, constituido por un continuum que conecta ciudades grandes, pequeñas, pueblos, campo, nuevas ciudades. Ahora bien, este espacio ilimitado desde el punto de vista físico y funcional está lleno de límites desde el punto de vista social, cultural y administrativo. Porque esta pretendida ciudad difusa, es también la ciudad fragmentada socialmente y administrativamente, la ciudad sin límites es, entonces, la ciudad de los límites (Nel-lo, 1998, 47). Es una ciudad que se ensancha al espacio global, deviene megalópolis, invade la naturaleza, se constituye en un entorno autosuficiente, la plaza y la calle, sustituidos por parques temáticos, shopping malls, enlazando solo a través de la autopista y el automóvil (Soler Amigó, 1998). El cambio es cualitativo e interesa tanto a la ciudad tradicional como a la nueva ciu- 
dad. Ya que el espacio dejado libre en la ciudad tradicional por la población y las empresas, constituye un valioso recurso para la construcción de la ciudad nueva, postmoderna, en las formas de la ciudad tradicional, o cómo diría Amendola (2000, 28-32) en la cáscara física de la ciudad tradicional. En ésta, los viejos edificios son rehabilitados y lanzados al mercado para un público dotado de un capital financiero adecuado a una residencia de servicios de tipo superior.

La arqueología como ciencia social debe incrementar su participación en el debate sobre la caracterización de la sociedad actual, interviniendo en él desde su propia reflexión epistemológica y práctica científica. Debate que viene encontrando, en occidente y más particularmente en los países mediterráneos, una de sus expresiones más significativas en el aspecto relativo a la configuración de la ciudad actual. Así pues, hablar de arqueología y modelos de ciudad significa hablar y defender una opción objeto, en los tiempos actuales, de discusión. Significa tomar postura en un debate que se podría resumir en dos posiciones:

1) - Defensa de la existencia de un concepto, de un modelo de ciudad que sirva de criterio de referencia. La existencia de un modelo hace posible resumir la ciudad en una visión de conjunto y establecer lo que cabe en dicho modelo y lo que se aleja de él.

2) - Defensa de una ciudad carente de punto de vista o de control desde los cuales unificarla y gestionarla. Una ciudad llena de confusiones, diversidades, desviaciones, actividades, sin límites...

La segunda posición, de gran éxito, viene a ilustrar lo que ya desde hace algunas décadas, se empezaba a definir como ciudad postmoderna que protagonizaba, de forma inexorable, el paisaje urbano de cada vez más amplias zonas de España. Ya señalé cómo nos encontrábamos ante un modelo de ciudad, porque contrariamente a lo que argumentaban sus defensores, respondía a un conjunto de pautas ordenadas y establecidas, que definían al modelo de ciudad de la globalización. Un modelo de ciudad que de triunfar y consolidarse, supondría el paso de un espacio social convivencial y colectivo, definitorio de la ciudad mediterránea, a un espacio definido por criterios individualistas (Olmo Enciso, 2002: 254). Un modelo de ciudad que ignora el pasado, a excep- ción de lo que se decide que conviene a las leyes del mercado, a partir de una resignificación del concepto de valor, y, por tanto, de la utilización del Patrimonio como pretexto. Algo radicalmente diferente de lo que ha caracterizado el modelo urbano generado a partir de la Ilustración y las revoluciones burguesas, que confería un papel destacado a los espacios históricos como contenedores simbólicos y materiales de la Memoria y, por tanto, como espacios a conservar.

Nuestros nuevos paisajes urbanos, en lo que se refiere a la planificación urbanística, se banalizan, son más uniformes y más aculturales, se han globalizado a través de la imagen de la "ciudad postmoderna". Quizás nos encontramos ante la crisis de una idea de Patrimonio que se ve amenazada por lo global y por la evanescencia del dominio postmoderno. No es que sea el fin de la Historia, sino más bien de una concepción de la Historia, de la Memoria, en la que la idea de Patrimonio se torna, de forma interesada, más abstracta. Y esta crisis de la ciudad europea conlleva una mutación concomitante de la noción de "ciudadanía urbana": si su espacio de expresión privilegiada - la ciudad - no se reconoce, la ciudadanía se convierte en una simple abstracción (Anny Vrychea, en Tsiomis, 1998:77-78).

Pero también la articulación de los espacios urbanos contemporáneos están reflejando los cambios de una sociedad que en sus inicios ya denominamos como del conocimiento, de las nuevas tecnologías, de la ciudad de la e-topía (Mitchell, 2001). Nuestros intercambios se producen cada vez más a través de una dimensión comunicativa que evita la mediación corpórea (Cacciari, 2009: 67), y a la vez que la dimensión corpórea se va diluyendo la ciudad va adelgazando en sus contenidos. Debemos preguntarnos si se puede hablar de ciudadanía sin un espacio convivencial, materializado a través de espacios de Memoria y socialización. Ya Lewis Munford advertía de los peligros del "caos" debido a la fase "neotécnica", lo que venía a incidir en un debate intrínseco al proyecto de Modernidad, la presencia y preocupación o defensa de lo "técnico" en la ciudad, esa constante que, entre otros, ya había preocupado a Ruskin, Morris, o posteriormente inspirado la "Mecanópolis" de Unamuno o la "Metrópolis" de Fritz Lang. Debate nunca abandonado, siempre presente, que en estos tiempos de la "Sociedad del Conocimiento" vuelve tener una importante presencia y reflexión debido a la 
hegemonía que en la vida cotidiana ha adquirido el uso de las nuevas tecnologías. Se defiende cómo el sistema digital de interconexión en red jugará el papel que desempeñaron sus predecesores -calzadas y acueductos romanos, canales del siglo XVIII, ferrocarril en el XIX, red eléctrica, autopistas...- como hitos significativos de metamorfosis a través de los avances tecnológicos en épocas anteriores (Mitchell, 2001: 19). Es revelador de todo este proceso la llamada de atención de este autor: "Ahora ya es evidente. La ciudad, tal y como la entendieron los teóricos urbanos desde Platón y Aristóteles hasta Lewis Mumford y Jan Jacobs, ya no es capaz de mantener su cohesión ni de cumplir su función como ocurría anteriormente. Es a causa de los Bits: ellos la han matado. El modo urbano tradicional no puede coexistir con el ciberespacio. No obstante, jviva la nueva metrópolis unida por la red de la era electrónica digital!" (Mitchell, 2001: 7). Esta afirmación, contenedora de una verdad parcial, aunque "in crescendo", se antoja algo naif, pero a todas luces inexacta. Los Bits no han matado a la ciudad, a nuestro modelo de ciudad convivencial la intentan, más que matar -que es algo inmediatoeliminar, un proceso progresivo y paulatino y, por tanto, más sofisticado, la especulación, las leyes de mercado, y ante todo una cierta indiferencia social. Esta interpretación de los Bits, ciberespacio, no forma parte de una determinada concepción dominante, en la actualidad, de lo que en realidad son infraestructuras, porque el problema es superestructural. Y este si que es el que define el modelo de ciudad actual.

Asépticamente esto es una clara evidencia que, sin embargo, hay que conectarla con una realidad social y así este sistema y sus indudables avances tecnológicos, contextualizando con una sociedad actual que apunta a un modelo de individualización y retraimiento de lo público, conlleva también graves riesgos de pérdida de capacidad convivencial y de abandono de la necesidad de espacios para la socialización. Porque el indudable salto cuantitativo comunicacional y su mejora de nuestra capacidad y calidad informativa, contienen como límite el que éstas se realizan mayoritariamente, desde espacios físicos individualizados. Es cierto que el citado autor, apuesta por la creación de un tejido urbano que ofrezca oportunidades a los grupos sociales para que se mezclen en lugar de mantenerse aislados "El portátil en el café de la plaza, en lugar del ordenador en la urbanización protegida" (ibidem: 88). Pero tal y como advirtió Manuel Castells, podríamos terminar con "ciudades duales: sistemas urbanos" polarizados espacial y socialmente entre grupos y funciones de alto valor añadido, por un lado, y grupos sociales devaluados y espacios degradados, por el otro (Castells, (1998: 33). Y en cualquier caso, nos estamos encaminando hacia una ciudad regulada por formas de derecho privado del que se van excluyendo lenta pero progresivamente los espacios públicos convivenciales, generados a partir de la densificación histórica, por espacios privados donde se consume y se socializa al dictado de las leyes de Mercado.

\section{2. ¿Y La Aroueología..., Estado de la CUESTIÓN O UNA CUESTIÓN SIN ESTADO?}

Es en relación a esta ciudad actual, concatenación de lugares y de "no lugares", para la que hay que plantearse como se define el carácter del proyecto de investigación de la arqueología urbana, máxime cuando la ciudad ya supera los límites de una estructuración urbana objeto del pasado. Todo ello obliga a que para hablar de arqueología y de su relación con los modelos de ciudad sea necesario establecer el marco de relaciones que sitúan a esta ciencia social dentro de las dinámicas de la sociedad actual.

Es cierto que la arqueología ha generado una abundante investigación y literatura sobre la ciudad en las diferentes épocas del pasado, que ha sido fundamental para que el conjunto de la sociedad elaborara toda una idea de pertenencia. Sin embargo, la participación de la arqueología en el debate sobre la ciudad actual y sus estrategias de futuro, tiene que basarse en la oferta de lo que nuestra ciencia genera para el conocimiento de la realidad urbana a partir de su construcción y reflexión epistemológica.

¿Qué aporta la arqueología a todo esto?. Desde luego no solo taxonomías, no solo tipologías urbanas, sino manifestaciones sociales como elemento transformador de un paisaje, en este caso, urbano. Para ello es necesario profundizar en los paradigmas urbanos que como fruto de nuestra investigación interpretamos, pero también entender y reflexionar sobre la base epistemológica a partir de la cual el proyecto de la modernidad ha ido construyendo su visión, nuestra visión, sobre la ciudad. Diferentes aspectos han confluido en cómo la arqueología española ha comenzado a tratar la cuestión urbana a partir de los años 80 del 
pasado siglo, que se resumen en una renovación conceptual y metodológica y en la implantación de un nuevo marco legal y normativo.

Es cierto que en España el concepto de urbanismo tiene una acepción en lo que se refiere al pasado de nuestras ciudades, fuertemente funcionalistas que no se detiene a reflexionar sobre la profundidad histórica de estas. Ya Bendala (2009: 23), señaló como en el contenido de la "urbanística", subyace la idea de que la proyección material de la ciudad se da prioritariamente, con casi exclusión de todo lo demás, en la urbe construida. En la urbanística, en la acepción indicada, se agotaría la materialidad de la ciudad, como si se estableciera una total identificación entre urbanismo material y urbe. Y esta ecuación insuficiente para entender la concepción de la ciudad en la Antigüedad, como ha sido puesto de relieve por la investigación moderna (ibidem), se revela, igualmente, insatisfactoria a la hora de definir el espacio urbano histórico desde la actualidad. Quizás éste sea uno de los aspectos centrales de la citada debilidad conceptual de la arqueología que no ha logrado generar una alternativa a la regulación urbanística y a las "trampas" del centro histórico como único espacio sacralizado a preservar. De hecho, desde la arqueología hemos aceptado y colaborado en la zonificación de la ciudad desde unos criterios que, por definición, son, o deberían ser, "exógenos" a nuestra ciencia, dado que otorgan un único valor referencial a los centros históricos. De esta forma, se han perpetuado espacios sacralizados por un concepto fosilizado, o que se prefiere fosilizado, el de Centro Histórico, lugar que se preserva y fuera del cual surge un excitante territorio pretendidamente "no-histórico" como campo de experimentación supuestamente libre de ataduras patrimoniales.

De hecho, el Centro Histórico visto desde la actualidad y desde la perspectiva de lo que aporta la arqueología al conocimiento del proceso histórico de las ciudades, es un anacronismo. Un anacronismo que debe ser superado, puesto que privilegia, fundamentalmente una visión elitista y en las últimas décadas interesada por la voracidad constructiva, del pasado urbano. Visión según la cual se prioriza para la investigación y tutela, todo lo que está situado en el interior de los perímetros de estos Centros Históricos, que en la mayoría de las ocasiones sacralizan espacios urbanos monumentales anteriores al siglo XIX. Quedan, por tanto, fuera de esta consideración legal de centro histórico definitorio de las señas de identidad de una ciudad, las áreas históricas del siglo XIX y XX que albergan los espacios productivos y de habitación ligados a la formación y consolidación de la sociedad industrial, o enteras zonas arqueológicas. Por el contrario, la arqueología, que no estudia monumentos sino espacios históricos - protagonistas de los procesos de cambio social a lo largo de la historia -, espacios que se han ido transformando y que han ido modificando el paisaje urbano, contextualiza todos estos espacios y de ahí la consideración de la ciudad como un yacimiento único y no jerarquizado. Yacimiento único que, generalmente, supera los limites declarados de los centros históricos españoles (Olmo Enciso, 2002: 248).

Para esta nueva consideración del espacio y el tiempo han sido fundamentales la consolidación de la arqueología como ciencia histórica, favorecida por la profunda renovación auspiciada por el procesualismo y el postprocesualismo, la renovación metodológica impulsada por la arqueología estratigráfica, así como la ampliación del tiempo histórico competencia de la investigación arqueológica. Factores todos estos que posibilitaron el desarrollo de otra orientación que permitía la superación del obsoleto concepto de centro histórico y su sustitución por el más verídico de Ciudad Histórica.

Todo esto, hay que relacionarlo con un proceso ya acometido en el ámbito europeo que propició la ampliación del concepto de Bien Cultural a todo aquello que constituían "los testimonios del pasado", lo que motivó la modificación del concepto de valor así como un crecimiento exponencial de gran calado de los elementos y espacios a proteger (Ricci, 1996: 15). El paso de una valoración basada en el carácter artístico de objetos y monumental de edificios y conjuntos, a una más amplia concepción del patrimonio que integraba todos aquellos bienes muebles e inmuebles y espacios que conservan testimonios de la actividad humana, supuso un positivo cambio de gran calado. En el caso de España éste se produjo tardíamente, en la década de los años 80 , con la consolidación democrática y quedó expresado en la Constitución de 1978 (Preámbulo y arts. 44.1 y 46) y la Ley 16/1985 de Patrimonio Histórico Español, que contenían disposiciones que estimulaban su conservación, su acrecentamiento y su disfrute, dentro del derecho a la Cultura, explicitado claramente en 
la Constitución como un derecho social (García Fernández, 2008: 92). A este respecto, hay que recordar, como el Preámbulo de la Ley de Patrimonio Histórico señala como "Los Bienes que lo integran se han convertido en patrimoniales debido exclusivamente a la acción social que cumplen, directamente derivada del aprecio con que los mismos ciudadanos los han ido revalorizando". Como consecuencia se desarrolló un concepto de patrimonio arqueológico en el que su investigación, conservación, tutela y difusión se encuadraban en línea con su carácter de dominio público emanado del mandato constitucional y de la legislación que subrayaba el, ya citado, carácter social de todo el Patrimonio Histórico. Todo ello formaba parte de la voluntad de construir un Estado de Bienestar y representaba una época -finales de los años 70 principios de los 80- caracterizada por la transición democrática y el consenso político y social de todos los sectores de la sociedad española.

Hay que destacar cómo desde entonces, en estos últimos treinta años, la situación del patrimonio arqueológico ha cambiado positivamente, aunque todavía se esté lejos de alcanzar el nivel deseable. Se puede argumentar que, en términos generales, en una parte apreciable de las ciudades españolas con un patrimonio arqueológico importante, se ha progresado de forma notable en la investigación, tutela, conservación e integración de los restos arqueológicos y, por tanto, en el conocimiento de su evolución histórica. Pero a pesar de estos avances, también es cierto que se ha asistido a una considerable pérdida de patrimonio como consecuencia de una poderosa política de expansión y renovación urbana, así como de construcción de infraestructuras en el territorio, ejecutada entre finales de los años 80 y la pasada década.

Las necesidades derivadas del planeamiento urbanístico y de infraestructuras produjeron la ampliación del campo de actuación arqueológica con el desarrollo obligatorio, tal y como marcaba la legislación, de intervenciones de carácter diagnóstico previas a la ejecución de las diferentes obras. Desde sus inicios se analizaron las experiencias europeas de Inglaterra, Francia e Italia, así como las diferentes normativas y cartas internacionales, a la hora de desarrollar estas estrategias. Sin embargo, la incapacidad de los nuevos departamentos de Patrimonio de las administraciones autonómicas y municipales, debido a sus escasos recursos humanos y materiales, para gestionar el volumen de intervenciones arqueológicas consecuencia de la citada eclosión produjo la externalización de la incipiente política de prevención. Todo ello provocó que se optara por derivar el modelo de intervención arqueológica preventiva a empresas privadas de arqueología que comenzaron a surgir en este momento impulsadas, en un principio, por parte de la Administración, cuyo papel quedó reducido, a partir de ese momento, a una labor centrada en la tramitación administrativa, control y resolución sobre la actividad arqueológica realizada. Por tanto, a finales de la década de los 80 se pasó del modelo de intervención pública, que había definido la gestión y la propia investigación arqueológica, a la creciente privatización de dicho modelo de intervención preventiva que supuso la aparición de la Arqueología Comercial (Olmo Enciso, 2012: 43). En definitiva, se asumió el modelo neoliberal anglosajón que prioriza la privatización del servicio (Parga Dans, 2011: 126), basándose para ello en las experiencias de Estados Unidos en los años 80 e Inglaterra a comienzos de los 90. No deja de llamar la atención cómo estas administraciones, a pesar de las diferentes ópticas autonómicas, basadas en una tradición de gestión y concepción pública del Patrimonio, acentuada por el mandato constitucional y legislativo ya citado, y en sintonía con otros modelos públicos como el francés o el italiano, optaran, sin embargo, por impulsar estas medidas privatizadoras y dieran origen al nacimiento de esa Arqueología Comercial. Nacimiento que, por tanto, supuso la aparición de un nuevo nicho de mercado vinculado a la explotación de los recursos arqueológicos.

Hay que mencionar que gracias al despegue de la Arqueología Comercial, la arqueología ha tenido en España un desarrollo espectacular en los últimos años. Sin embargo, este mayor peso, en cuanto a número de intervenciones, ha venido impulsado por coyunturas de oportunidad y conveniencia, generalmente ajenas a una planificación racional de necesidades y objetivos de dichas intervenciones o a programas de investigación concretos. Las intervenciones arqueológicas de este tipo se han convertido en una codiciada pieza dentro de un mercado realmente incontrolado. Desgraciadamente, en la mayoría de las ocasiones este tipo de intervenciones quedan como mera justificación administrativa, que no contempla su finalidad de investigación y enriquecimiento histórico, y se han plegado a las exigencias y presión 
del mercado inmobiliario, convirtiéndose, prácticamente, en un mero trámite administrativo. (AAVV, 2000, p. 69). Y esto ha producido otro grave problema al que se enfrenta la arqueología española, como es la disociación entre la investigación arqueológica y la arqueología comercial.

Este conflicto entre la Arqueología Académica, o de investigación, y la Arqueología Comercial, que no sólo es característico de la realidad española, dado que también se ha producido en Estados Unidos, Reino Unido o Italia, es en realidad un falso e interesado conflicto. El divorcio entre dichas "arqueologías", se fundamenta sobre la supuesta base de que sus profesionales tienen diferentes objetivos en el tratamiento de la práctica arqueológica, dentro del proceso de deconstrucción, en este caso arqueológica, propiciado por las políticas neoliberales. Este modelo, ya fue en su momento criticado y cuestionado, desde la defensa y la consideración de que todo lo que amplía el conocimiento histórico es investigación (AAVV, 2000, p. 65-72; Olmo Enciso, 2002: 245). Se investiga no solo para conocer el pasado, sino también para restaurarlo, conservarlo, difundirlo y presentarlo de forma didáctica, favoreciendo, por tanto, el disfrute de la sociedad sobre su Patrimonio Histórico.

La escasa tradición en la reflexión sobre la arqueología urbana, el desinterés en reclamar su papel en un proyecto de tanto alcance social como es la discusión sobre el modelo de ciudad, hay que relacionarlos, en gran parte, con el insuficiente tratamiento que se le otorga en el ámbito académico universitario. En este sentido, la debilidad conceptual de la arqueología a la hora de tratar la cuestión urbana procede de su práctica ausencia en los programas universitarios de grado y postgrado. En la gran mayoría de ellos sigue primando la concepción tradicional de la enseñanza de una arqueología basada en la periodización histórico-cultural, y más concretamente en épocas determinadas de esta, y motivada por los intereses científicos individuales de los docentes. En ellos se observa un escaso tratamiento de la arqueología medieval y una clamorosa ausencia de la relativa a épocas posteriores y recientes, fundamentales para entender los depósitos arqueológicos de nuestras ciudades, al representar la gran mayoría de su potencialidad arqueológica. Todo ello ha derivado en un problema de formación con carencias en una estructura curricular que no desarrolla competencias acordes con las nuevas necesidades científicas y de tutela. Se ha abandonado la ciudad como objeto de investigación y, por tanto, la actuación arqueológica ha recaído exclusivamente en manos de una Administración, que como hemos analizado, ha impulsado y dirigido esta hacia otro tipo de actores. También es cierto que desde gran parte de las administraciones se ha visto con cierto recelo la participación de la Universidad en las estrategias y ejecución de la planificación urbana.

Todo lo hasta aquí expuesto se fundamenta en la necesidad de iniciar una reflexión y su transmisión a la práctica académica y docente sobre el futuro de nuestras ciudades. Reflexión que debe basarse y sustentarse en un análisis que inserte el conocimiento del pasado de nuestros paisajes urbanos y lo combine con toda la reflexión y debate sobre el modelo de ciudad. Porque una cosa es evidente, la posición ante el Patrimonio no es inocente ni aséptica, requiere un compromiso claro acerca de su función, su tutela, su divulgación y su disfrute. En relación con toda la carga epistemológica que caracteriza a este debate en el campo del urbanismo, la arqueología no debe seguir anquilosada aceptando ser solo "un estudio previo", esa "pesada carga", que hay que soportar por imperativo legal. La Universidad debe involucrarse más en los organismos de tutela y favorecer e impulsar la investigación. Porque solo desde la Universidad, desde la práctica intelectual que ésta representa, se puede y se debería generar e impulsar una reflexión pausada y científica, a la larga mucho más beneficiosa y productiva para la sociedad y libre de las ataduras y presiones a las que se ven sometidas la arqueología comercial y, en cierta forma, también la Administración.

Desde una óptica general, habría que concluir cómo la situación de la arqueología urbana se caracteriza por la diversidad de circunstancias existentes, como consecuencia de varios factores. Entre éstos cabría destacar: los diferentes grados de aplicación, y de cumplimiento, de la normativa legal por parte de las diferentes Administraciones (Nacional, Autonómica, Local); la carencia de una política, por parte de estas mismas administraciones, basada en proyectos de gestión homogéneos a la hora de plantear las estrategias de prevención, investigación, conservación o eliminación, y divulgación del patrimonio arqueológico urbano; la falta de coordinación entre las diferentes administraciones para una correcta gestión del patrimonio arqueológico; 
una asombrosa escasez de planes de investigación y de formación en arqueología preventiva y urbana por parte de la Universidad. La insuficiente o inexistente presencia de ésta y otras instituciones científicas en este tipo de proyectos y la ausencia de intervención de la Administración como garante de unas condiciones mínimas en materia de financiación de los proyectos, así como de las condiciones laborales de los trabajadores de la arqueología. En este sentido, conviene remarcar la existencia de un consenso generalizado entre los especialistas a favor de una estandarización legal y metodológica que desarrolle unas directrices básicas homogéneas emanadas desde el propio entorno administrativo (Parga Dans, 2010: 183). Todo ello formaría parte de un debate generado en los últimos años sobre el futuro de lo que se ha venido denominando arqueología preventiva en España, defendiendo la necesidad de incidir y ampliar dicho carácter preventivo (AA.VV, 2000; Salvatierra, 2004, y e.p ; Olmo Enciso, 2002 y 2012; Quirós, 2005).

\section{Arqueología urbana es investiga- CIÓN O NO ES ARQUEOLOGÍA.}

Se iniciaba este trabajo expresando cómo la asunción para el tratamiento del paisaje urbano, de los conceptos de espacio y tiempo, permite también presentar la Memoria urbana desde otra perspectiva valorada desde la arqueología, el concepto de Ciudad Histórica. Por tanto, desde un espacio más verosímil y que supera los límites impuestos a partir de los cuales se ha sacralizado y fomentado la consideración de lo "histórico" de la ciudad actual. Todo ello, significa entrar en el debate sobre el urbanismo, aportando la reflexión teórica ofrecida desde la arqueología. Porque es evidente que la arqueología forma parte de una intervención global sobre el tejido urbano, por tanto, participa con pleno derecho, en el debate sobre el modelo de ciudad y tiene que ser inscrita en los proyectos de desarrollo urbano formando parte de sus procesos de investigación y planificación. Esta planificación urbanística, en tanto que opera sobre un espacio social, la ciudad, definiendo proyectos de futuro, es un campo de trabajo interdisciplinar en el que confluyen varios especialistas. Por tanto, es necesario dirigirnos hacia una figura de urbanista colectivo que integre a todos aquellos profesionales arquitectos, arqueólogos, historiadores, sociólogos, ingenieros, economistas....competentes en la articulación de las líneas de futuro de un determinado espacio social. Todo ello muy alejado de la mayoría de los proyectos de planificación urbanística que, salvo valiosas excepciones, adolecen de un fuerte funcionalismo.

La realidad transmite la ausencia, ya mencionada, de un debate teórico en profundidad y extensión sobre la presencia de la arqueología urbana dentro del contexto de la ciencia arqueológica en general, pero también partícipe en la discusión sobre el modelo de ciudad que en la actualidad se dirime en la esfera social y científica. Esto supone apostar por un proyecto interdisciplinar que, promovido, apueste por la coordinación y el trabajo conjunto de universidades, organismos públicos de investigación y las administraciones competentes. El desafío debe conducir a hacer partícipe a la arqueología de los procesos conceptuales, proyectuales y normativos rectores de la transformación del medio urbano y territorial. Esto supone la reivindicación de la arqueología como una actividad científica que se construye desde la contemporaneidad y, por tanto, inmersa y partícipe en el debate sobre la configuración de la sociedad actual. Supera el marco reduccionista de una arqueología supeditada a las directrices marcadas por la planificación urbanística y territorial, así como por las necesidades del mercado, que es el que ha caracterizado a la arqueología urbana española en su mayor parte. La solución no se encuentra en la reprobación a las consecuencias del modelo, sino en la crítica a los orígenes de éste. No hay que centrarse en los instrumentos sino en los fines que los crearon (Olmo Enciso, 2012: 46).

\section{Evaluación y Selección.}

A partir de este carácter de investigación, la arqueología debe participar en la conceptualización del espacio urbano, mejorando las estrategias e instrumentos de evaluación y selección en la primera fase del proyecto. Para la buena ejecución de éstas, constituye un requisito fundamental el rigor y solidez de su carácter preventivo. Hay que partir de la premisa fundamental de que un programa de intervención nunca podrá considerarse completo si no forma parte de un verdadero proyecto de investigación que defina en todos sus aspectos las estrategias precisas de intervención y desarrolle los interrogantes que plantea el inherente proceso de evaluación del depósito arqueológico. Este proyecto de investigación tiene que 
contemplar como uno de sus aspectos fundamentales, la evaluación del depósito arqueológico destinada a mostrar antes de intervenir, la potencialidad y valor de dicho depósito. A este respecto M. Carver, autor de referencia con una fecunda y dilatada reflexión sobre la arqueología urbana desde los años 80, había advertido sobre los peligros de la acumulación de informaciones y materiales, así como de la imposibilidad de transformar éstos en conocimiento histórico, consecuencia de un elevado número de intervenciones, la inmensa mayoría de las cuales no habría aportado prácticamente nada al conocimiento de la ciudad (Carver, 1983: 52; 1990; 2003: 111-112). Se ponía el dedo en la llaga sobre la imposibilidad de transformar la mayoría de la información y materiales obtenidos por la arqueología urbana en una fuente arqueológica productora de conocimiento histórico. Tema especialmente preocupante en nuestro país, donde la enorme cantidad de intervenciones arqueológicas y la subsiguiente acumulación de materiales, la inmensa mayoría sin estudiar, bien poco han aportado al conocimiento histórico de nuestras ciudades. Esta acumulación de datos se justificaba desde una coartada neopositivista, mediante la cual la mera recolección de éstos ya proporcionaba por sí misma conocimiento histórico, lo que por otra parte conllevaba la eliminación, de un plumazo, de la complejidad de la construcción histórica (Quirós, 2005: 116; Salvatierra, e.p.). Se borraban así décadas de renovación arqueológica y su propio carácter como ciencia. Se deconstruyó la consideración de la ciudad como yacimiento único, fragmentándose su estudio en solares, con diferencias en la intensidad y rigor de las aplicaciones metodológicas, y la arqueología retrocedió a su consideración como "estudio previo" y carga necesaria por imperativo legal antes de abordar un proyecto de renovación urbana. Esta visión fragmentada e incompleta de la ciudad, unida a una mínima, o inexistente, divulgación, se hace especialmente más dolorosa si nos detenemos a pensar las enormes inversiones, en millones de euros, que ha supuesto todo este quehacer.

Sin embargo, la ciudad es un yacimiento único, un único contexto arqueológico y como tal tiene que ser tratado. Carver ya había defendido cómo el éxito de la arqueología urbana dependía de una estrategia regional de planificación de la investigación. Estrategias que se basaban en la evaluación de la potencialidad de los depósitos arqueológicos, y todo ello a partir de una aproximación teórico-metodológica sistemática en las que la estratificación debía condicionar la investigación, ya que consiente, siempre y cuando fuera bien muestreada, construir una historia independiente de otras fuentes. Por tanto, se trata de construir una historia de la ciudad fundamentada por los procesos de estratificación. Un conocimiento eficaz de las referencias históricas de la ciudad no puede realizarse sino es a partir de una planificación, de un proyecto, que implique una evaluación y también una selección. Evaluación y Selección, constituyen dos etapas fundamentales de la investigación sobre las que hay que tomar decisiones científicas que se trasladen no solo a la generación de conocimiento histórico, sino también al desarrollo normativo.

El mejor instrumento para aplicar este proceso evaluativo y selectivo lo constituye la Carta Arqueológica de Riesgo. Es verdad que estas cartas desde su origen y aplicación inicial en Inglaterra han ido evolucionando y su concepto ha sido sometido a numerosas interpretaciones y reevaluaciones. Pero constituyen valiosos instrumentos que no tratan de documentar solo lo conocido, sino de identificar lo previsible, lo posible, lo desconocido. Supone obtener una base que contenga todos los parámetros reconocibles y evaluables a partir de los cuales determinar las jerarquías que nos sintamos en disposición de establecer. Este pasaje es el momento más difícil ya que presupone el principio de elección y por tanto de selección. Pero es un pasaje ineludible, por lo que es necesario abrir un debate de naturaleza cultural, que defina, o redefina, la relación que queremos instituir con el Pasado, con su Memoria, y, en nuestro caso, con el fósil de tal Memoria (Gelichi, 2008: 11).

Con ello entramos en un campo insuficientemente tratado en España, al igual que en otros países de nuestro entorno, el de la selección. Ya ha sido puesto de manifiesto por A. Ricci cómo toda estrategia de conservación implica una más candente y dolorosa, como es la selección. Selección destinada a establecer la convivencia entre preexistencias y nuevas intervenciones, desde la perspectiva que investigar el patrimonio arqueológico supone producir un descarte y alejar la tentación, tan asentada en la profesión, de creer que acumular fragmentos de preexistencias equivalga, per se, a acumular una memoria (Ricci, 1996: 25 y 
54; 2006: 74). Hay que reconocer que esto no constituye algo novedoso para los arqueólogos, puesto que estamos acostumbrados a realizar constantes selecciones en las que optamos por primar o favorecer en los yacimientos el estudio de unos periodos frente a otros, o privilegiar el análisis de determinados materiales, etc. Sin embargo, no deja de ser sorprendente cómo la comunidad científica haya eludido el problema de gobernar el descarte, la selección, en el ámbito urbano (Gelichi, 2008: 11). Y es que esta selección es fundamental en la conciliación del patrimonio arqueológico urbano con el desarrollo urbano. Máxime cuando la intervención arqueológica origina un estancamiento producido por el bloqueo del equilibrio entre lo que se genera -nuevos restos y materiales para conservar- y la imposibilidad de absorción de estos en términos de investigación y de valoración dirigida al disfrute ciudadano. Como consecuencia, la arqueología queda así atrapada entre los procesos de transformación de nuestras ciudades y la utopía de congelar e inmovilizar todo el ámbito patrimonial (Ricci, 1996: 24; 2006: 70). Andreina Ricci en un sugestivo libro (2006) ha incidido en este aspecto sobre la diferente visión de profesionales que operan en la ciudad, señalando cómo los arqueólogos nos justificamos a menudo lamentando la indiferencia que a veces muestran los arquitectos en relación con la Historia de los lugares donde pretenden construir. Así en los nuevos desarrollos urbanísticos, esta actitud viene relacionada con una "Utopía del arquitecto" que sueña con un espacio como un "no-lugar" neutro que pueda ser rellenado por las formas extraídas del inmenso repertorio de su memoria personal y, por tanto, define un proyecto de cualquier manera realizable. En el otro tipo de espacios, aquellos protegidos patrimonialmente, se presenta otra impenetrabilidad opuesta a la anterior. Esta es la "Utopía del Conservador del Patrimonio", negadora de las necesidades de una ciudad viva, que debe transformarse, y que se defiende como un modelo teórico puro. Por tanto, a la Utopía del Arquitecto, con su no-lugar neutro se opone la "Utopía del Conservador del patrimonio", que opera sobre un "no-lugar", opuesto al precedente, tan denso de memoria que resulta impenetrable. Una distinción que recuerda la expuesta por Lewis Mumford, con su Utopía de la Reconstrucción, que reproyecta en el mundo externo una nueva visión de la realidad; y la "Utopía de la Fuga", refugio en el que nos retiramos cuando entramos en contacto con una realidad dura, demasiado complicada de superar y demasiada áspera de afrontar (Ricci, 2006:61-62).

Estas utopías, en el fondo esconden una falta de elaboración conceptual y de reivindicación del urbanismo en espacios históricos como una práctica científica y también cultural, así como nuestro papel como científicos sociales. Porque la arqueología participa y defiende un modelo de ciudad, pero esta argumentación debe ir acompañada, de una reflexión generada a partir de nuestra disciplina, sobre cómo a partir del conocimiento histórico se ahonda en un análisis de la ciudad como construcción social, y cómo a partir de él se aportan ideas al debate sobre un modelo de ciudad, y se defiende el ya citado papel del urbanista como un sujeto colectivo.

\section{Divulgación.}

Un aspecto esencial de todo este proceso, generalmente olvidado o tratado tangencialmente, y en cualquier caso fuera del proceso de construcción de la planificación urbanística, es el de la divulgación. Es cierto que en nuestro país en los últimos treinta años se han ejecutado innumerables y valorables acciones de musealización de restos arqueológicos urbanos, pero también es cierto que, salvo destacables excepciones, éstas han consistido en la presentación del final de un proceso y en la puesta en valor de zonas ya socialmente evaluadas por su importancia histórica. Como bien ha señalado A. Ricci, en nuestra sociedad la asociación entre monumentos, restos del pasado e identidad, se da por descontada, es algo natural y sedimentado en la opinión pública, sin embargo, cuando pretendemos documentarla en los restos patrimoniales urbanos nos enfrentamos ante realidades inesperadas y contradictorias (Ricci, 2006: 109). Por tanto, ha llegado el momento de extender la estrategia pedagógica a todo el proceso, máxime cuando estamos defendiendo el carácter del espacio urbano, de la Ciudad Histórica, como yacimiento único sin límites espaciotemporales.

Hay que desarrollar proyectos que favorezcan y permitan transferir con enorme rapidez los resultados de la investigación al ciudadano haciéndoles partícipes del propio proceso de conocimiento, que es la investigación. Y es esta divulgación una fase fundamental que se debe ir construyendo a la par que las de evaluación y 
selección. Si, como decía Benjamin, la calle es la morada del ciudadano, si la ciudad es un espacio convivencial, si es un ámbito de producción cultural, habrá que convenir que la divulgación del pasado es una parte ineludible de nuestro quehacer y se constituye en uno de los pilares centrales de nuestra labor como interpretes de la ciudad. Y esto significa entrar en un debate de actualidad en Occidente, el de la progresiva separación entre la Investigación Histórica y el Uso Público de la Historia (Ricci, 2006:10-12 y 27-31). Esto obliga a una transformación radical de la perspectiva del arqueólogo obligándole a una relación más seria con la contemporaneidad, ya que la arqueología ofrece una potencialidad extraordinaria desde el punto de vista didáctico-pedagógico, pero es también un instrumento peligroso si se utiliza inapropiadamente ya que genera modificaciones ostensibles de la ciudad y de su percepción como espacio histórico, y a veces poco meditadas (ibidem: 29-30). Porque todo esto hay que relacionarlo con una época en la que la mayoría de la producción cultural es cada vez más efímera y evanescente. Proceso que afecta claramente a la Ciudad Histórica, contenedora simbólica y material de la Memoria, donde actualmente se ignora el Pasado a partir de una resignificación del concepto de valor a través del cual se hacen las excepciones pertinentes que convengan a las leyes del mercado. Y surge así, la ciudad escaparate, porque la mutación de la ciudad histórica no es sólo estructural, sino que es en primer lugar cultural. Se produce así la "tematización de la ciudad", proyecto según el cual las ciudades tradicionales, nuestras ciudades históricas, sirven cada vez menos para vivir y se proponen como destinos turísticos, factorías de producción de experiencias, aventuras, visiones. Algo que ya se venía anunciando " $L a$ ciudad ya no existe, salvo como espejismo cultural para turistas" (McLuhan, 1967). Desde esta consideración, la más extremista de nuestra sociedad del ocio y de nuestra economía terciarizada, habría llegado el momento de explotar a la ciudad histórica como el parque temático más excitante (Verdú, 2001). En este modelo encaja la trivialización postmoderna, en la que el espacio ha sido sustituido por el símbolo, por el icono simbólico, ha significado una alteración del tiempo, de la percepción del pasado. Al desaparecer el espacio y permanecer el icono, el tiempo, el pasado, se ha reconstruido y se han eliminado las referencias sociales. Se ha construido así una nueva referencia cultural a partir de la banalización.
Sin embargo, por la propia esencia de la arqueología, por su caracterización, una de sus labores dentro de la planificación del modelo de ciudad debe ser la participación en las estrategias educadoras, haciendo partícipe a la ciudadanía de todo un proceso de construcción y desarrollo de la interpretación del pasado. Significa involucrarse en un proyecto interdisciplinar, también urbanístico, sobre la ciudad educadora, una ciudad con personalidad propia, que reconozca y reivindique, ejerza y desarrolle, además de las funciones tradicionales -económica, social, política y de prestación de servicios también una función pedagógica en el sentido de asumir una responsabilidad y una vocación en el objetivo de la formación, la promoción y el desarrollo de todos sus habitantes, de toda la sociedad (Soler Amigó, 1988), a través de la plasmación, en este caso, de la memoria colectiva. En definitiva, tal y como transmitía Halbwachs (1987: 147): No hay memoria colectiva que no se despliegue en un cuadro espacial; es en el espacio, en nuestro espacio [...] al que tenemos que dirigir nuestra atención: es sobre él en el que se debe fijar nuestro pensamiento para que esta o aquella categorías de recuerdos puedan reaparecer.

Nuestras ciudades, expresión de una realidad histórica compleja y diversa, constituyen el ámbito más importante de intervención sobre el Patrimonio y, a menudo más de lo deseado, de degradación y destrucción de éste. La arqueología en la ciudad, tal y como se ha venido defendiendo, debe ser el planeamiento del conjunto de acciones destinadas a preservar los restos arqueológicos, o a definir las estrategias y criterios de descarte de estos, una vez que hayan sido exhaustivamente documentados, y es, asimismo, la investigación e integración del pasado arqueológico urbano en el urbanismo del futuro. Porque no existe una ciudad homogénea e inmutable, sino más bien diferentes modelos de ciudades que, compartiendo un mismo espacio en el tiempo, han producido un ámbito de memoria que hemos convenido en llamar Ciudad Histórica.

Hay un aspecto fundamental sobre el que conviene reflexionar, como es el relativo al valor de reivindicación que se otorga al patrimonio arqueológico urbano, como consecuencia de una cierta instrumentalización a partir de su función simbólica de producción de Memoria. La arqueología en la ciudad desarrolla un debate entre el 
concepto de identidad y el de ciudadanía. La reelaboración postmoderna del concepto de identidad, ha encontrado un campo abonado en la arqueología ya que ha permitido recuperar - ¿alguna vez se había abandonado?- uno de los paradigmas de la escuela histórico-cultural, la identidad etnicista. La crisis económica actual fomenta la aparición de tendencias excluyentes y, por tanto, la apropiación de la ciudad por parte de un sector que reivindica para si la ciudad como espacio identitario-etnicista. Sin embargo, la práctica arqueológica nos refleja la ciudad como un espacio histórico en el que integrar la diversidad, a través de la realidad pluriestratificada que la investigación ofrece. Por tanto, desde la arqueología ¿Qué tipo de ciudad se defiende? ¿La ciudad identitaria o la ciudad de ciudadanos?

Sin embargo, no hay que olvidar que trabajamos sobre espacios históricos y, por tanto, socialmente concebidos. Que cuando se proyecta sobre espacios históricos, se proyecta sobre espacios patrimoniales y sociales, y ahí el papel del arqueólogo -como el de otros muchos profesionales- es fundamental, dentro de ese ámbito interdisciplinar que debe ser el urbanista colectivo. En este sentido, a la hora de acometer proyectos de planeamiento urbano es tarea de los responsables, tal y como acertadamente expresó G. Carlo Argan, sincronizar los fenómenos urbanos actuales en relación con el desarrollo diacrónico, desde el remoto pasado hasta el futuro, de una determinada situación urbana. Porque los espacios "vividos", objeto de nuestra investigación, memoria de la cotidianeidad urbana, deben integrarse en el planeamiento urbano desde la perspectiva que la identidad de una comunidad es la suma de los elementos que conforman el pasado y el presente de los ciudadanos y que deben ser conservados y proyectados para el futuro (AA.VV, 2000: 72; Olmo Enciso, 2002: 255). Por la propia esencia de la arqueología que, fundamentalmente, aporta conocimiento histórico pero que además posee una función social, es fácil deducir por que tipo de ciudad debe apostarse. Se participa en la defensa y aplicación de un modelo de ciudad que tenga profundidad histórica, que preserve la diversidad y peculiaridad, frente a las homogeneidades y globalizaciones que definen modelos de ciudad fuertemente funcionalistas y sujetos a intereses especulativos y contrarios a una diversidad urbana que tanto desde la diacronía como de la sincronía ha caracterizado y debe seguir caracte- rizando el espacio ciudadano. En definitiva, tal y como transmitió Italo Calvino en "Las ciudades invisibles" se trata de: Buscar y saber reconocer que y cuales cosas, en medio del infierno, no son infierno y hacerlas pervivir dándoles su espacio.

\section{Bibliografía:}

AMENDOLA, G. (2000): La Ciudad Postmoderna. Ed. Celeste, Madrid.

AA.VV. (2000): Un futuro para la memoria. Sobre la administración y disfrute del Patrimonio Histórico Español. Ed. Visor. Madrid.

BENDALA GALÁN, M., (2009): "La urbanística antigua en los tres decenios últimos" estudio preliminar a la $3^{\mathrm{a}}$ edición de A. GARCÍA BELLIDO: Urbanística de las grandes ciudades del mundo antiguo: 15-44, Ed. CSIC. Madrid.

CACCIARI, M. (2009) La Cittá, Rimini.

CARVER, M. (1983): "Valutazione, strategia ed analisi nei siti pluriestratificati", Archeologia Medievale, X: 49-71. Florencia.

CARVER, M. (1990): "Digging for data: archaeological approaches to data definition, acquisition and analysis", en R. FRANCOVICH, D. MANACORDA (eds): Lo scavo archeologico: dalla diagnosi all' edizione, III Ciclo di Lezioni sulla Ricerca Applicata in Archeologia (Certosa di Pontignano, 6-18 novembre 1989): 45-120. Florencia.

CARVER, M. (2003): Archaeological value and evaluation. Ed. Societá Archeologica Padana, Mantova.

CARVER, M. (2009): Archaeological Investigation. Ed. Routledge, Londres-Nueva York.

CASTELLS, M. (1998): "The informational city is a Dual City: Can it Be Reversed?" en D.A. SCHÖN, B. SANYAL, W. MITCHELL (eds) High Technology and Low Income Communities. MIT Press, Cambridge.

CHOAY, F. (2007): Alegoría del patrimonio, Ed. Gustavo Pili, Barcelona.

GARCÍA FERNÁNDEZ, J. (2008): Estudios sobre el Derecho del Patrimonio Histórico. Madrid.

GELICHI, S. (2008): “Strategie per la costruzione di una carta territoriale delle potenzialità: dai siti al paesaggio", en S. GELICHI, C. NEGRELLI (eds): A Misura d' Uomo. Archeologia del territorio cesenate e valutazione dei depositi: 9-11. Florencia. 
HALBWACHS, M., (1987): La memoria collettiva, Milán. (traducción del original frances, aparecido póstumamente en 1950: La mémoire collective, Paris, 1950).

LEFEBVRE, H. (1991): The Production of Space. Blackwell, Oxford 1991 (original en francés, 1974).

McLUHAN, M. (1967): The Alchemy of Social Change, Nueva York.

MITCHELL, W.J. (2001): e-topia.”vida urbana, Jim, pero no la que conocemos. Ed. Gustavo Gili, Barcelona.

MUMFORD, L. (1997): Storia dell' Utopia, Ed. Donzelli. Roma.

NEL-LO, O. (1998): "La ciutat il-limitada i la ciutat futura", en NOGUÉ FONT, J., La ciutat. Visions, anàlisis i reptes, Girona.

OLMO ENCISO, L. (2002): “Arqueología y modelos de ciudad: una reflexión desde España”, A. RICCI (ed.), Archeologia e Urbanistica: 243-256. Ed. All'Insegna Del Giglio, Firenze.

OLMO ENCISO, L. (2012): "L' Archeologie preventive en Espagne", Archeopages, Institut National de recherches archéologiques préventives, Janvier: 2012:42-46, Paris.
PARGA DANS, E. (2010): Innovación y emergencia de un servicio intensivo en conocimiento: el caso de la Arqueología Comercial. Universidad de Santiago de Compostela. Santiago de Compostela.

QUIRÓS CASTILLO, J.A. (2005): “¿Excavar en las ciudades o historiar las ciudades? El debate sobre la Arqueología Urbana a la luz de algunas experiencias europeas", Arqueología y Territorio Medieval, $\mathrm{n}^{\circ}$ 12.1: 107-130, Jaén.

RICCI, A., (1996): I mali dell' abbondanza. Considerazioni impolitiche sui beni culturali, Ed. Lithos/Cester, Roma.

RICCI, A., (2006): Attorno alla nuda pietra. Archeologia e cittá tra identitá e progetto. Ed. Donzelli, Roma.

SALVATIERRA, V. (2004): “Arqueología urbana. Investigación y profesión", Anales de Arqueología Cordobesa, vol. 15: 45-59. Córdoba.

SALVATIERRA, V. (en prensa): "Arqueología y Urbanismo", en AAVV: La Materialidad de la Historia. Ed. Akal. Madrid.

TSIOMIS, Y. (ed) (1998): Ville-cité. Des patrimoines européens. Ed. Picard. Paris. 